\title{
EKSPLORASI ETNOMATEMATIKA PADA KERAJINAN KAYU DI DESA TUTUL KECAMATAN BALUNG SEBAGAI BAHAN AJAR GEOMETRI
}

\author{
Aina Kholifatuzzuhro ${ }^{1}$, Sunardi ${ }^{2}$, Lioni Anka Monalisa ${ }^{2}$, \\ Program Studi Pendidikan Matematika, FKIP, Universitas Jember \\ Jalan Kalimantan 37 Kampus Tegalboto Jember 68121 \\ E-mail: kholifatuzzuhroaina@gmail.com
}

\begin{abstract}
This study aims to explore anything ethnomatematics related to woodwork in Tutul Village, Jember. Woodcraft is a craft made from wood. This type of research is a study using a qualitative approach with ethnographic design. Research subjects in this study were craftsmen and owners of "Ara Collections" wood production houses. In this study the object is focused on bracelets, necklaces, and keeping. Based on the results of the study, it can be seen that wood crafts have mathematical elements. The mathematical elements found are ball, tube, cube, integrated cone, rectangular flat, circle, parabolic, ellipsoid, hyperbole, hyperbole, geometric patterns, reflection, dilation, and congruence and concordance. The teaching material made is in the form of a geometry test package related to ethnomatematics in wood crafts in Tutul Village, Balung Sub-District, Jember.
\end{abstract}

Keywords: Ethnomatematics; Woodcraft; Geometry; Teaching Materials

\section{PENDAHULUAN}

Matematika adalah cabang ilmu yang mempelajari tentang bilangan dan bentuk-bentuk operasional yang digunakan di dalam bilangan. Menurut para ahli pendidikan matematika, matematika adalah ilmu yang membahas pola atau keteraturan (pattern) dan tingkatan (order). Sekali lagi hal ini menunjukkan bahwa guru matematika harus memfassilitasi siswanya untuk belajar berpikir melalui keteraturan (pattern) yang ada [8]. Geometri merupakan salah cabang ilmu dalam matematika yang diawali oleh sebuah konsep pangkal, yakni titik. Titik kemudian digunakan untuk membentuk garis dan garis akan menyusun sebuah bidang. Pada bidang akan dapat mengonstruksi macammacam bangun datar dan segi banyak. Berikut ini merupakan macam-macam

\footnotetext{
${ }^{1}$ Mahasiswa S1 Prodi Pendidikan Matematika FKIP Universitas Jember

${ }^{2}$ Dosen Prodi Pendidikan Matematika FKIP Universitas Jember
} 
bangun datar. Misalnya segitiga, persegi persegi panjang, jajar genjang, belah ketupat, trapesium, layang-layang, dan lingkaran. Selain bangun datar, terdapat juga bangun ruang balok, kubus, prisma, limas, tabung, kerucut, dan bola. Terdapat juga kesebangunan dan kekongruenan dalam matematika. Menurut Geometry Keyterm mengatakan bahwa dua bangun datar (segi banyak) dikatakan sebangun jika sudut-sudut yang bersesuaian memiliki ukuran yang sama dan sisisisi yang bersesuaian memiliki proporsi yang sama [10]. Dua bangun dikatakan kongruen jika semua sisi-sisi yang bersesuaian sama panjang dan ukuran sudutsudut yang bersesuaian sama besar. Matematika memiliki materi tentang transformasi geometri. Transformasi geometri memiliki beberapa sifat, di antaranya adalah translasi (pergeseran), rotasi (perputaran), refleksi (pencerminan), dan dilatasi (perbesaran).

Menurut Sahertian eksplorasi memiliki sebuah arti yaitu, suatu kegiatan yang dilakukan dalam rangka pembelajaran dan mengacu pada sebuah penelitian (penjajakan), dengan tujuan memperoleh pengetahuan lebih banyak tentang keadaan atau suatu benda dengan cara melakukan pengumpulan data untuk menghasilkan suatu bentuk perupaan yang baru [7]. Etnomatematika adalah program penelitian yang fokusnya pada hubungan antara matematika dan Budaya. Lebih jauh lagi bahwa matematika merupakan hasil dari sejarah sosial dan proses budaya yang dikembangkan dengan kontribusi dari berbagai masyarakat dan budaya [1]. Etnomatematika juga memberikan pembelajaran yang bermakna bagi siswa. Pembelajaran dengan pendekatan etnomatematika lebih relevan dan lebih bermakna bagi siswa [2]. Etnomatematika adalah cara-cara khusus yang digunakan oleh suatu kelompok budaya atau masyarakat tertentu dalam aktivitas matematika [6]. Kebudayaan menjadi dasar filsafah kehidupan, sementara pendidikan menjadi penjaga utama kebudayaan, karena peran pendidikan adalah membentuk orang untuk berbudaya [9].

Kerajinan kayu merupakan salah satu komoditas yang banyak dibuat dan diperjual belikan di Desa Tutul Kecamatan Balung Jember. Bentuk-bentuk dari kerajinan kayu menyerupai bangun-bangun serta konsep-konsep yang terdapat dalam matematika. Misalnya kerajinan kayu yang berupa aksesoris gelang dan 
kalung. Mengikuti perkembangan zaman, bentuk bulir dibuat beragam dan menyerupai bangun ruang pada matematika. Konsep matematika yang ditemukan pada kerajinan kayu akan dibuat menjadi sebuah bahan ajar paket tes geometri.

Berdasarkan pemaparan di atas peneliti ingin mengetahui lebih jelas tentang etnomatematika pada kerajinan kayu di Desa Tutul Kecamatan Balung, Jember dan membuat produk berupa bahan ajar paket tes geometri mengenai bab bangun datar, bangun ruang dan pola geometri. Tujuan penelitian ini adalah mengungkap konsep dan unsur geometri pada kerajinan kayu di Desa Tutul Kecamatan Balung, Jember kemudian membuat bahan ajar berupa paket tes geometri mengenai bab bangun datar, bangun ruang dan pola geometri. Bahan ajar adalah kumpulan materi pembelajaran yang disusun dengan sistematis.

\section{METODE PENELITIAN}

Pada penelitian ini metode yang digunakan adalah penelitian menggunakan pendekatan kualitatif dengan design etnografi. Penelitian kualitatif adalah penelitian yang memahami fenomena yan dialami oleh subjek penelitian. Secara holistic, dan dengan cara deskripsi dalam bentuk kata-kata dan bahasa, pada suatu konteks khusus yang alamiah dan dengan memanfaatkan berbagai metode alamiah. Etnografi dapat diartikan sebagai penulisan tentang kelompok budaya. Penelitian kualitatif dapat mengungkap dan menjelaskan masalah yang ada di dalam penelitian dengan lebih mendalam, penelitian lapangan dan observasi bertujuan untuk mendapatkan informasi secara langsung.

Daerah penelitian adalah tempat yang akan digunakan penelitian oleh peneliti. Daerah yang akan digunakan pada penelitian ini terletak di desa Tutul, kecamatan Balung, kabupaten Jember. Langkah pertama yang dilakukan pada penelitian ini adalah pendahuluan. Pada tahap pendahuluan dilaksanakan observasi awal di Ara Collections untuk menentukan topik permasalahan yang dijadikan objek penelitian. Langkah kedua pada penelitian ini adalah membuat draft instrumen penelitian, yaitu pedoman observasi dan pedoman wawancara. Penelitian ini diambil 3 orang sebagai subjek penelitian yaitu seorang pemilik rumah produksi dan 2 orang selaku pengrajin kayu di rumah produksi Ara 
Collections. Langkah ketiga pada penelitian ini adalah validasi draft instrumen penelitian. Langkah keempat adalah pengumpulan data.

Metode pengumpulan data yang digunakan yaitu observasi, wawancara, dan dokumentasi. Wawancara ini dilaksanakan dengan mewawancarai subjek penelitian untuk memperkuat dan mendukung data-data yang telah didapatkan pada saat observasi. Langkah kelima adalah analisis data. Setelah dikumpulkannya data-data pada saat observasi, wawancara dan dokumentasi, selanjutnya akan dilakukan analisis data dengan tujuan penelitian yaitu mendeksripsikan etnomatematika pada kerajinan kayu di Desa Tutul Kecamatan Balung. Ketika telah didapatkan deskripsi etnomatematika pada kerajinan kayu dilanjutkan dengan langkah keenam yaitu adalah pembuatan produk berupa bahan ajar paket tes yang sesuai dengan tujuan penelitian. Langkah ketujuh pada penelitian ini adalah menarik kesimpulan dari penelitian yang telah dilakukan.

\section{HASIL DAN PEMBAHASAN}

Kerajinan kayu yang diteliti pada penelitian ini adalah berfokus pada aksesoris gelang, kalung dan alat dapur yaitu telenan. Pada tabel 1 berikut ini disajikan hasil unsur-unsur matematika yang terkandung dalam kerajinan kayu di Desa Tutul, Kecamatan Balung, Jember.

Tabel 1. Unsur-unsur etnomatematika pada kerajinam kayu di Desa Tutul

\begin{tabular}{|c|c|l|}
\hline No. & \multicolumn{1}{|c|}{ Gambar } & \multicolumn{1}{|c|}{ Etnomatematika } \\
\hline 1. & $\begin{array}{l}\text { a. Pola Geometri } \\
\text { b. Tabung } \\
\text { c. Elipsoida } \\
\text { d. Kesebangunan } \\
\text { dan } \\
\end{array}$ & \\
& Kekongruenan \\
\hline
\end{tabular}




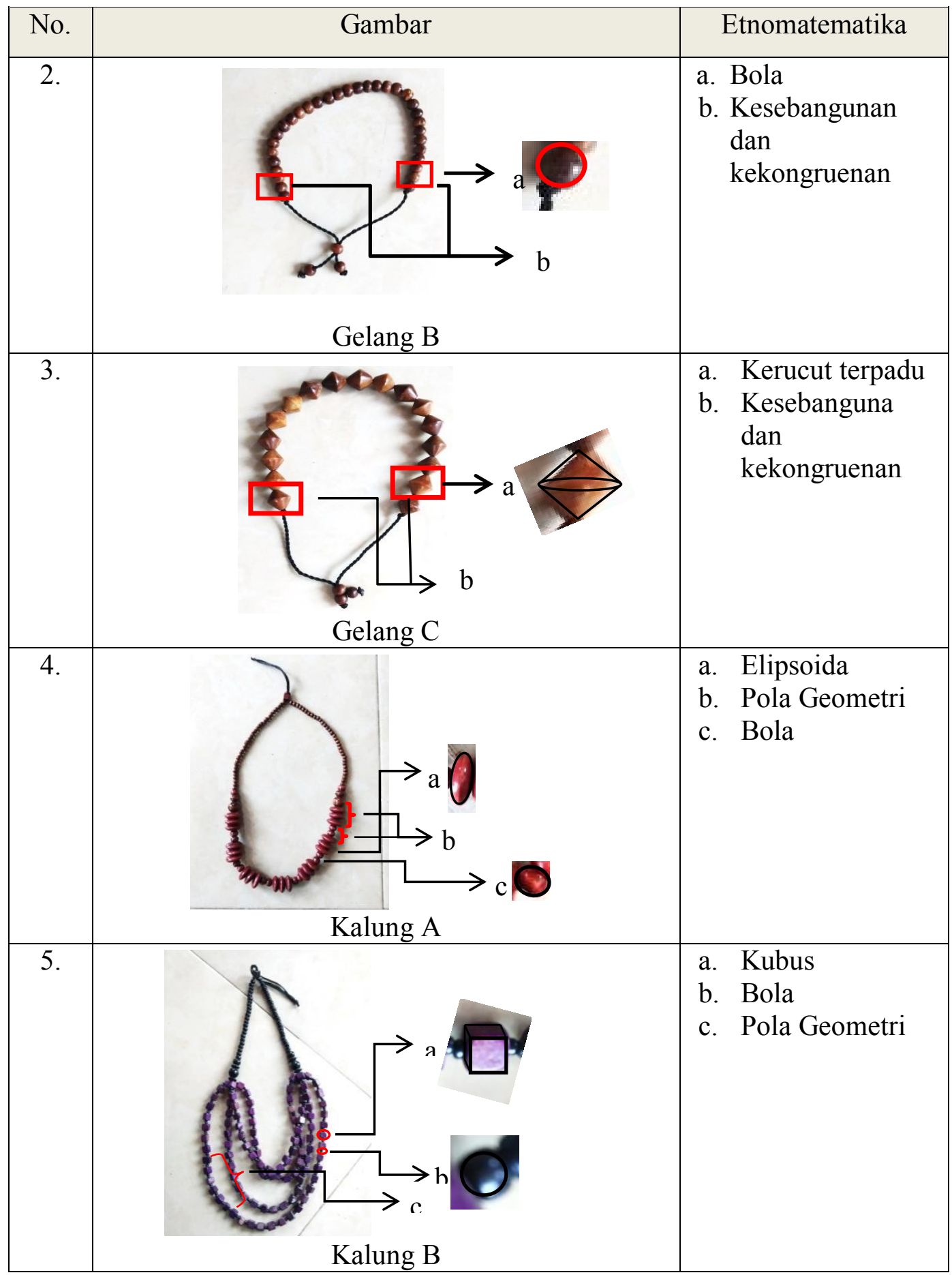




\begin{tabular}{|l|l|l|}
\hline No. & Etnomatematika \\
\hline 6. & $\begin{array}{l}\text { a. Elipsoida } \\
\text { b. Paraboloida } \\
\text { c. Bola }\end{array}$ \\
\hline 7. & \\
\hline
\end{tabular}




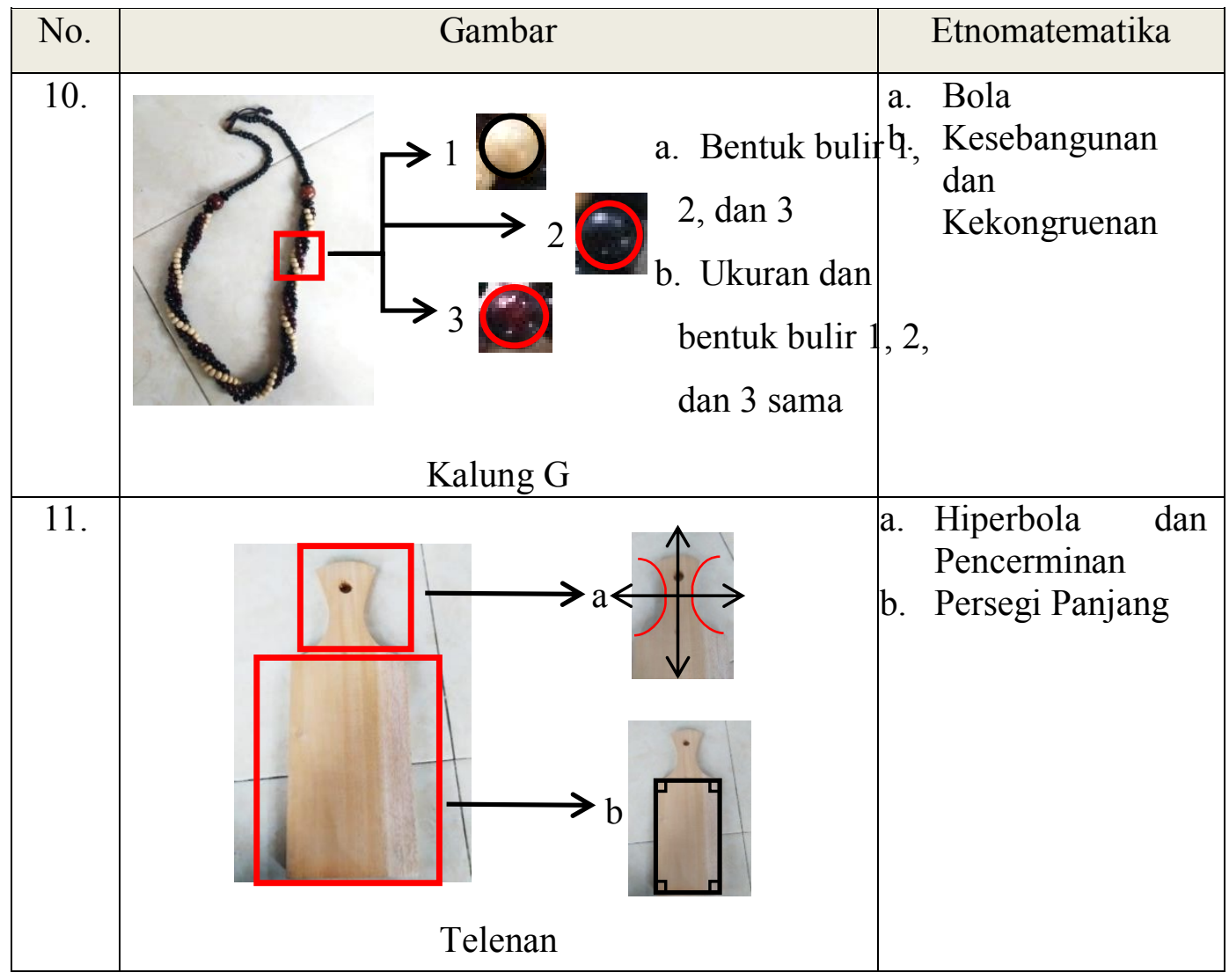

Penelitian ini menemukan konsep bangun ruang lingkaran, elipsoida, dan paraboloida. Konsep bangun ruang bola ditemukan pada bulir gelang B, kalung A, kalung B, kalung C, kalung D, kalung E, kalung F, dan kalung G. Penelitian oleh Putri [4] yang mengacu pada bentuk geometri dalam kesenian rebana dan memfokuskan pada bentuk fisik yang terkait dengan konsep lingkaran dan prisma. Hal ini sesuai pada penelitian ini yaitu ditemukan konsep lingkran pada kalung F. Lingkaran pada bulir kalung $\mathrm{F}$ ini memiliki ketebalan pada bagian sisi lingkarannya. Bentuk bola ini dibuat dengan berbagai ukuran masing-masing aksesoris. Pembuatannya yaitu dengan membuat bentuk kubus terlebih dahulu. Panjang sisi kubus ini akan menjadi panjang dari diameter dari bola. Pembuatan bulir ini masih dengan cara satu persatu dengan perkiraan ukuran yang sama dan dengan ketrampilan pengrajin sehingga menghasilkan bentuk yang sama dan serupa. Bulir bangun ruang bola berukuran kecil dan bulir bangun ruang bola yang lebih besar melewati tahapan proses pembuatan yang sama. 
Bentuk bangun ruang tabung dapat ditemukan pada gelang A atau biasa disebut model kendang oleh pengrajin. Pembuatan model kendang ini adalah dengan membuat bentuk balok kemudian dihaluskan satu persatu untuk dibentuk bangun tabung. Bentuk bangun datar persegi panjang dapat ditemukan pada bagian badan telenan. Telenan menyerupai bangun datar persegi panjang karena dilihat dari ciri-ciri bangun persegi panjang yaitu memiliki dua pasang sisi yang sejajar dan sama panjang, serta keempat sudutnya siku-siku. Telenan ini dibuat dengan mengikuti sketsa atau para pengrajin menyebutnya mal. Bentuk bangun ruang kubus dapat ditemukan pada kalung B. Cara membuat bulir berbentuk kubus adalah dengan cara membuat kayu berbentuk balok panjang terlebih dahulu kemudian dipotong dengan bentuk kubus. Untuk mengukur panjang dari sisi kubusnya agar sama pada saat memotong, diberi jarak pada tempat memotongnya. Sehingga ketika dilakukan proses pemotongan hasilnya semua ukurannya sama.

Bentuk elipsoida dapat ditemukan pada bagian bulir gelang A, kalung A, dan kalung C. Untuk membuat bulir berbentuk elipsoida adalah dengan cara membuat bentuk pipih menyerupai bentuk lingkaran. Kemudian dimasukkan ke dalam suatu alat yang terdapat mata pisau untuk membentuk bulir menjadi bentuk elipsoida. Setelah dimasukkan dan ditekan maka keluarlah bulir dengan bentuk elpisoida yang diinginkan. Untuk membuat bulir bentuk ini dilakukan dengan satu per satu memasukkannya kedalam alat khusus tersebut. Bentuk hiperbola dapat ditemukan pada bagian bagian atas telenan. Bagian atas dari telenan yang berbentuk hiperbola dibuat dengan mengikuti mal atau sketsa seperti pada analisis bentuk bangun datar persegi panjang pada poin sebelumnya. Hal ini sejalan dengan penelitian yang dilakukan oleh Qoyimah [5] mengenai cara pembuatan kerajinan kayu dan mengidentifikasi bentuknya dengan konsep-konsep matematika yang terkait. Pada penelitian ini memfokuskan pada konsep bangun ruang sisi lengkung, luas dan keliling persegi, kekongruenan dan kesimetrisan.

Konsep pola geometri dapat ditemukan pada susunan gelang A, kalung A, kalung B, kalung $\mathrm{C}$, kalung $\mathrm{D}$, dan kalung F. Menentukan pola pada proses peroncean dilakukan dengan cara mencoba-coba pola susunan agar terlihat indah. Selain untuk memperindah tampilan, juga disesuaikan dengan bentuk dari bulir. 
Misalnya pada gelang A terdapat pola susunan bulir berbentuk tabung dengan bulir berbentuk bola. Hal ini bertujuan agar gelang dapat melengkung dengan sempurna. Jika hanya terdapat bulir berbentuk tabung saja bentuknya akan tidak dapat melengkung dengan baik. Konsep dilatasi dapat ditemukan pada susunan kalung D dan kalung E. Bentuk bulir tersebut sama, yang membedakan adalah pada ukurannya. Penyusunan bulir yang lebih besar berasa di tengah dengankan yang lebih kecil pada bagian pinggir kanan dan kirinya (kalung D dan kalung E). Konsep paraboloida dapat ditemukan pada susunan kalung C. didapatkan ukuran bulir pada bagian kanan dan kiri dari kalung $\mathrm{C}$ sama. Bentuk ini menyerupai bentuk paraboloida. Proses pembuatannya adalah dengan di ampelas satu persatu. Pengrajin membuatnya dengan ukuran perkiraan namun menghasilkan hasil yang sama dan seragam.

Konsep bangun ruang kerucut dapat ditemukan pada susunan gelang C. Cara pembuatan bulir pada gelang $\mathrm{C}$ adalah dengan membuat bentuk seperti tabung terlebih dahulu. Kemudian diputar dengan suatu alat dan pengrajin membuang bagian pinggir kanan dan kirinya sehingga tersisa bagian ujung lancip. Bentuk ini menyerupai bentuk dua bangun kerucut yang digabungkan pada bagian alasnya. Hal tersebut relevan dengan penelitian yang sejenis yaitu penelitian yang dilakukan oleh Lubis dkk [3] yaitu tentang bentuk geometri pada kerajinan kayu yaitu bangun ruang kerucut dan bangun ruang tabung. Konsep pencerminan dapat ditemukan pada telenan. Telenan ini dibuat dengan mengikuti sketsa atau mal yang dimiliki oleh pengrajin. Bentuk semua telenan ini sama satu sama lain. Pada bagian ujungnya yang melengkung memiliki kecekungan dan tinggi yang sama pada kanan dan kirinya. Bentuk ini menyerupai bentuk hiperbola. Bagian badan dari telenan ini menyerupai bangun datar persegi panjang karena bagian dua pasang sisi sejajarnya sama panjang dan semua sudutnya adalah siku-siku. Konsep kesebangunan dan kekongruenan dapat ditemukan pada gelang B, gelang C, dan kalung G. Dibuat dengan satu persatu namun dengan ukuran yang relatif sama atau bahkan sama persis.

Informasi yang diperoleh dari analisis data yang telah dilakukan menunjukkan bahwa pada setiap kerajinan kayu di Desa Tutul Kecamatan Balung 
Jember memiliki unsur matematika. sehingga diperoleh informasi bahwa etnomatematika yang ditemukan pada komponen kerajinan kayu di Desa Tutul Kecamatan Balung Jember adalah bangun bola, persegi panjang, tabung, kubus, kerucut terpadu, elipsoida, paraboloida, hiperbola, pola geometri, dilatasi, pencerminan, dan kesebangunan \& kekongruenan.

\section{KESIMPULAN}

Berdasarkan hasil analisis data dan pembahasan, dapat diambil kesimpulan bahwa pada kerajinan kayu ditemukan etnomatematika di dalam bentuknya. Konsep matematika bangun ruang bola banyak ditemukan pada gelang dan kalung. Konsep bangun datar persegi panjang ditemukan pada badan telenan. Konsep tabung yang terdapat pada gelang yang dilubangi bagian alas dan tutupnya. Konsep bangun kubus terdapat pada bulir kalung. Konsep bentuk elipsoida ditemukan pada bulir kalung. Konsep paraboloida terdapat pada bulir kalung. Pembuatan bentuk praboloida ini tidak menggunakan mal atau sketsa sehingga pembuatan bergantung pada perkiraan pengrajin. Konsep hiperbola ditemukan pada bagian atas telenan. Konsep pola geometri didapatkan pada pola penyusunan bulir pada gelang dan kalung. Terdapat pola penyusunan bersadarkan jumlah, misalnya 2-1-2-1 dan 3-2-3-2. Konsep dilatasi terdapat pada bulir kalung. Biasanya penyusunan bulir dengan bentuk yang sama namun ukuran yang berbeda.

Bahan ajar paket tes yang dihasilkan pada penelitian ini adalah adanya menunjukkan keterkaitan antara konsep matematika dengan kerajinan kayu di Desa Tutul, Jember. Penyusunan paket tes ini berdasarkan penelitian yang telah dilakukan yaitu etnomatematika pada kerajinan kayu di Desa Tutul, Jember. Paket tes terkait etnomatematika pada kerajinan kayu di Desa Tutul Kecamatan Balung, Jember dapat diakses melalui tautan berikut ini https://drive.google.com/file/d/1fQnVAflLGLwhzzIPaOjFtAYSIASlqu5/view?us $\mathrm{p}=\mathrm{drivesd \textrm {k }}$ 


\section{DAFTAR PUSTAKA}

[1] E. Albanese and M. Prina, Nutrition and Dementia, Alzheimer's Disease International (ADI), 2014.

[2] C. Iluno and J. I. Taylor, "Ethnomathematics: The Key to Optimizing Learning and Teaching of Mathematics," IOSR Journal of Research \& Method in Education (IOSR-JRME), vol. 3, no. 1, pp. 53-57, 2013.

[3] S. I. Lubis, A. Mujib, and H. Siregar, "Eksplorasi Etnomatematika pada Alat Musik Gordang Sambilan" Edumatika, vol. 1, no. 2, pp. 1-10, 2018.

[4] L. I. Putri, "Etnomatematika, Kesenian Tradisional Rebana, Pembelajaran Matematika. IV(1),"Jurnal Unissula, vol. 4, no. 1, pp. 21-31. 2017.

[5] F. Qoyimah and S. A. Perdana. "Analisis Etnomatematika Gasing Berembang Kota Piring Tanjungpinang Kepulauan Riau dan Keterkaitan terhadap Topik dalam Pembelajaran Matematika," Repository Umrah (2018, http://repository.umrah.ac.id/1634/1/QOYIMAH-140384202018-FKIP2018.pdf) (diakses 10 Agustus 2019)

[6] I. Rachmawati, "Eksplorasi Etnomatematika Masyarakan Sidoarjo," MATHEdunesa, vol. 1, no. 1, pp. 1-8, 2012.

[7] P. N. Rumeksa and K. A. Saftyaningsih. "Eksplorasi Serat Kapuk (Ceiba Pentandra) Dengan Tenik Tenun ATBM dan Kempa," Media Neliti (2012, https://media.neliti.com/media/publications/241647-none-ae177ee1.pdf) (diakses 10 Agustus 2019)

[8] F. Shadiq, Pembelajaran Matematika: Cara Meningkatkan Kemampuan Berpikir Siswa. Graha Ilmu, 2014.

[9] B. Ulum, M. T. Budiarto, and R. Ekawati, "Etnomatematika Pasuruan : Eksplorasi Geometri Untuk Sekolah Dasar Pada Motif Batik Pasedahan Suropati. 1(1)," Prosiding SI MaNIs (Seminar Nasional Integrasi Matematika dan Nilai Islami), Malang: UIN Malang, pp. 70-78, 2017, Cetak.

[10] T. Wahyu, H. Abdoellah, T. W. Handayani, and T. Cardiah. "Geometric Ornaments Synthesis In Chinese Mosque," Open Library Telkom University (2016, https://libraryeproceeding.telkomuniversity.ac.id/index.php/bcm/ article-/viewFile/5743/5720) (diakses 20 Agustus 2019) 